\title{
Gestión contable de propiedad, planta y equipo bajo las Normas Internacionales de Información Financiera (NIIF) para el sector funerario y de servicios exequiales
}

\author{
Financial Management of Property, Plant and Equipment under the \\ International Financial Reporting Standards (IFRS) on the Funeral Sector \\ and Mortuary Service
}

\section{DOI: https://doi.org/10.33262/visionariodigital.v3i2.1.543}

Janeth Alexandra Abad Retete. ${ }^{1}$, Cecilia Ivonne Narváez Zurita. ${ }^{2}$ \& Juan Carlos Erazo Álvarez ${ }^{3}$

\begin{abstract}
Currently, in Ecuador, the Resolution 06.Q.ICI.004, (2006).08.21 establishes the requirement to adopt the International Financial Reporting Standards (IFRS) by small and medium-sized enterprises registered on the Superintendence of Companies. The resolution sets up that the companies provide financial information in accordance to the international standards, and, in turn, the results show high indexes of reliability, integrity, and comprehensibility on the process of recognition, measurement, presentation, and financial disclosure.

The adoption of these norms brings implicit modifications on the accounting treatment affecting mainly the group of Property, Plant and Equipment, which implies to the companies a before and an after of its implementation.

Accordingly, this article serves as a guide for Ecuadorian companies of the funeral sector regarding recognition procedures, registration, measurement, valuation, and

\footnotetext{
${ }^{1}$ Universidad Católica de Cuenca. Posgradista Maestría en Contabilidad y Auditoría jaabadr932@psg.ucacue.edu.ec

${ }^{2}$ Universidad Católica de Cuenca, Subdirección de Posgrado, Cuenca, Ecuador, inarvaez@ucacue.edu.ec

${ }^{3}$ Universidad Católica de Cuenca, Subdirección de Posgrado, Cuenca, Ecuador, jcerazo@ucacue.edu.ec
} 
presentation of effective Financial Management of Property, Plant, and Equipment. Therefore, a description of the context of NIIF 16, NIC17, NIC40, and NIC36 was carried out to analyze the changes under the current legal framework. Next, a diagnosis of the company identified the most significant difficulties for the implementation of these norms. Finally, a financial management structure was developed based on procedures to facilitate understanding of recognition, measurement, and validation of property, plant, and team.

Keywords: Property, Plant and Equipment, International Financial Reporting Standards, Accounting Data, revaluation, Operational Lease, recognition, measurement.

\section{Resumen.}

Actualmente en Ecuador la adopción de las Normas Internacionales de Información Financiera (NIIF) en las pequeñas y medianas empresas que reportan a la Superintendencia de Compañías, es una obligatoriedad establecida mediante la Resolución 06.Q.ICI.004 de 2006.08.21, la misma que tiene por finalidad que la información financiera presentada por las empresas registradas en el país sea similar con los estándares internacionales y a su vez, presente altos índices de fiabilidad, integridad y comprensibilidad en los procesos de reconocimiento, medición, presentación y revelación de la información financiera.

La adopción de estas normas trae implícitas modificaciones en el tratamiento contable, afectando especialmente al grupo de propiedad, planta y equipo, lo cual conlleva a las empresas a un escenario antes y uno después de su aplicación.

En este sentido, el presente artículo se constituye en una guía para las empresas del sector funerario y servicios exequiales registradas en el Ecuador, en lo referente a los procedimientos de reconocimiento, registro, medición, valoración y presentación de información para una efectiva gestión contable y tributaria de propiedad, planta y equipo. Para éste efecto, se realizó una descripción del contexto de las NIIF 16, NIC17, NIC40 y NIC36, a fin de analizar los cambios que incorpora el marco normativo vigente en el país, seguido se efectuó una diagnóstico en la empresa objeto 
de estudio, en donde se identificaron las principales dificultades para la implementación de estas normas y finalmente se desarrolló una estructura de gestión contable basada en procedimientos que facilitan la comprensión del reconocimiento, medición y valoración de propiedad, planta y equipo.

Palabras claves: Propiedad, planta y equipo, Normas Internacionales de Información Financiera, revalorización, arrendamiento operativo, reconocimiento y medición.

\section{Introducción}

La economía mundial se ha visto inmersa en un proceso de cambios vertiginosos en los últimos tiempos, lo cual ha impulsado y acelerado la búsqueda de un lenguaje común para presentar información contable de las empresas. Los cambios en la economía mundial, así como el proceso de la globalización, han presionado por afianzar un proceso que permita lograr una verdadera conjunción contable, como consecuencia de que cada día más países se adhieren al mismo. Esta situación implica que se debe evolucionar de una aplicación de principios contables locales hacia la aplicación de normas contables bajo estándares internacionales. Al respecto, los autores Díaz, Durán y Valencia (2012) afirman que los procedimientos de armonización contable desarrollados en las últimas décadas han llevado a consolidar los estándares internacionales reflejados en el modelo contable conocidos como Normas Internacionales de Información Financiera (NIIF).

\section{Evolución y tendencias de la contabilidad.}

Gómez (2003) aborda la evolución de la contabilidad y señala que a través de los años, la contabilidad ha sido percibida como la ciencia o técnica de registrar los hechos económicos en el momento que suceden, que permiten determinar el beneficio económico y la toma de decisiones oportunas, direccionado al cumplimiento del objetivo principal de la razón social de la entidad; sin embargo, bajo su apreciación, considera que se están dejando de lado la relevancia que tiene para resolver problemas concretos de las organizaciones. La contabilidad con todas las herramientas que presenta, es una fuente fidedigna de información para conocer su situación problemática y la forma de solucionarlos. "La contabilidad, no solo debe limitarse a servir al mercado, sino a la sociedad en su conjunto". (Rueda, 2012, p. 231). En la tabla 1 se presentan definiciones de contabilidad de reconocidos autores en función de las 
actividades que desarrollan las empresas a nivel local, nacional e internacional.

Bravo Señala que la contabilidad nace como una ciencia, ofreciendo al profesional

(2011) las pautas mediante las técnicas de analizar, clasificar, registrar para resumir en los estados financieros todas las operaciones que se han efectuado, permitiendo conocer la situación económica y financiera al término del año contable.

Cano (2013) Conceptualiza a la contabilidad como un sistema de información tradicional que sirve a interese de usuarios internos y externos, siempre enmarcada en los principios contables y normas actualizadas, con el fin de presentar estados financieros como punto final del proceso, mismos que deben estar disponibles para los directivos de la empresa así como para inversionistas o financistas que requieren información de la situación actual de la empresa con la finalidad de ver la posibilidad de invertir en la misma.

Santos Define a la contabilidad desde el punto de vista creativo, señalando que la (2016) misma consiste en aprovechar una ambigüedad o carencia de una norma, técnica o procedimiento contable, para implementar una diversidad de opciones que no están contempladas en las leyes, pero que no perjudica al fisco ni a la empresa que los registra, más bien satisface las necesidades de los directivos, en su afán de brindar información económica y financiera objetiva a todos los usuarios de los rubros de los estados financieros.

\section{Normas Internacionales de Información Financiera (NIIF) Antecedentes de las NIIF}

Monge (2005) menciona que la contabilidad también evoluciona con las exigencias que se viven en la actualidad, y con la entrada agresiva de la globalización, se ha visto necesario la elaboración de nuevas normas y principios contables que serán muy útiles en los distintos mercados potenciales siendo así comparables y comprendidos por los diferentes usuarios de la información, fortaleciendo de esta forma la transparencias de los hechos económicos de las organizaciones que interactúan en estos mercados. En el año 2002 se aprobó el reglamento para la aplicación de las NIC o Normas Internacionales de Información Financiera NIIF en la Unión Europea, y consecutivamente otros países lo hicieron en sus respectivos escenarios empresariales.

Las Normas Internacionales de Contabilidad NIC y las Normas Internacionales de Información Financiera NIIF son emitidas por la Junta de Estándares Internacionales de Contabilidad (IASB por sus siglas en ingles), quienes son los encargados de analizar de manera frecuente las normativas actuales en contraposición con la realidad de las empresas, y de ser necesario hacer los cambios pertinentes con el fin de lograr una verdadera armonización de la información y presentar estados financieros comparables con todos los 
sectores empresariales del mundo, para ser analizados por los diferentes inversionistas según Bohórquez (2015).

Peña y Bastidas (2007) aseveran que la aplicación de las NIC en el procesamiento de su información contable es una tendencia mundial y por consiguiente debe estar a la vanguardia de los cambios significativos; adicionalmente menciona que a través de la globalización los escenarios son dinámicos y que obligan a las empresas a equiparar su lenguaje contable y financiero con el resto del mundo. En Ecuador inicia su aplicación obligatoria en el año 2010 para todas las entidades supervisadas y controladas por la Superintendencia de Compañías.

Por su parte, Coral y Gudiño (2014) señalan que el objetivo de las NIC y NIIF es precisamente postear un marco conceptual que direccione la elaboración y estructuración de los balances generales como propósito primordial, logrando con ello ser objetivos y analíticos al momento de comparar los resultados obtenidos en los estados financieros de períodos anteriores ocasionados en la empresa y con los de otras empresas relacionadas con la misma actividad que operan en los mercados internacionales, señala además que es un requisito fundamental para participar en dichos mercados que la empresa procese su información con estas normas, considerando que los preceptos contenidos en las NIC y NIIF no son aplicables para periodos intermedios.

Bajo este contexto, Hansen (2012) refiere la revisión del cuerpo normativo exclusivo para las pequeñas y medianas empresas (PYMES), en donde se detallan claramente las características de los estados financieros, sus elementos y cuentas mínimas en los juegos de estados financieros, entre otros asuntos de importancia relativa, que hacen de las NIIF para PYMES una ventaja importante para desarrollar información confiable para la toma de decisiones.

\section{Diferencias entre las NIC, NIIF completas y NIIF para las pymes en el reconocimiento de la propiedad, planta y equipo.}

Parte de las diferencias que existen entre estos importantes postulados se los puede visualizar en el trabajo de Peña (2013), en el mismo se aprecia cómo se van analizando algunos postulados de las NIIF y la convergencia que se ha hecho en Venezuela, denotando que cada país debe realizar una evaluación minuciosa entre lo estipulado en las normas y sus necesidades internas, tomando en cuenta a su vez que una norma internacional no podrá estar por encima de las disposiciones legales de un país, por importante que sea jamás se antepondrá a los preceptos internos.

A continuación, se presentan algunas diferencias entre las NIIF completas y NIIF para pymes según Hansen (2012): 
Tabla 1. Diferencias NIIF PYMES y NIIF Completas

\begin{tabular}{|c|c|}
\hline NIIF para PYMES & NIC o NIIF Completas \\
\hline $\begin{array}{l}\text { No permite el modelo de revaluación para medir a } \\
\text { la PPE tras e. reconocimiento inicial, solo permite } \\
\text { el modelo del costo. }\end{array}$ & $\begin{array}{l}\text { Permiten el modelo de revaluación y también el } \\
\text { modelo del costo. }\end{array}$ \\
\hline $\begin{array}{l}\text { Los costos por préstamos para adquisición o } \\
\text { construcción de un activo no son capitalizables, } \\
\text { son considerados como gastos del periodo. }\end{array}$ & $\begin{array}{l}\text { Estos costos si son capitalizables de acuerdo a la } \\
\text { NIC } 23\end{array}$ \\
\hline $\begin{array}{l}\text { Se requiere una revisión del valor residual, vida útil } \\
\text { y método de depreciación de PPE, solo si hay un } \\
\text { indicio de algún cambio significativo. }\end{array}$ & $\begin{array}{l}\text { Requieren de una revisión anual del valor residual, } \\
\text { vida útil y método de depreciación. }\end{array}$ \\
\hline $\begin{array}{l}\text { Dentro de la propiedad planta y equipo están los } \\
\text { activos no corrientes mantenidos para la venta }\end{array}$ & $\begin{array}{l}\text { Se excluyen los activos no corrientes mantenidos } \\
\text { para la venta y son tratados por la NIIF } 5\end{array}$ \\
\hline $\begin{array}{l}\text { La PPE aplica a las propiedades de inversión que } \\
\text { no pueden ser medidas con fiabilidad. }\end{array}$ & $\begin{array}{l}\text { La PPE no aplica a las propiedades de inversión } \\
\text { cuto costo no pueda ser medido con fiabilidad. }\end{array}$ \\
\hline $\begin{array}{l}\text { Están redactadas en lenguaje sencillo, con } \\
\text { orientación sobre cómo aplicar los principios y } \\
\text { requerimientos de revelación. }\end{array}$ & $\begin{array}{l}\text { Incluye mucha más información para la orientación } \\
\text { sobre cómo aplicar los principios y requerimientos } \\
\text { de revelación. }\end{array}$ \\
\hline
\end{tabular}

Fuente: (Hansen, 2012).

\section{Teorías y principios contables en la propiedad, planta y equipo basados en las Normas Internacionales de Información Financiera para pymes.}

El desarrollo de un conjunto de normas y principios para las PYMES es coherente con el objetivo de la Junta de Normas Internacionales de Contabilidad (International Accounting Standards Board - IASB)-, buscando el interés público de carácter global que sean de alta calidad, comprensibles y de cumplimiento obligado, que requieran información de alta calidad, transparente y comparable reflejada en los estados financieros que suministran información sobre la situación financiera, el rendimiento y los flujos de efectivo que generan para ayudar a los usuarios que requieran de esta información de las pymes al momento de analizar el costo - beneficio, la capacidad para asumir los riesgos, el alcance y la amplitud de la pericia contable disponible para cumplir con las leyes y políticas internas y externas de las entidades de regulación fiscal de una determinada jurisdicción (Ramírez y Suárez, 2012).

\section{Propiedad, planta y equipo bajo NIIF}

Santos (2008) señala que toda empresa necesita de activos fijos para desarrollar sus actividades, en este sentido, la cantidad y tipo de propiedad planta y equipo que requiere la entidad depende de su giro y planes de desarrollo empresarial; de esta forma contabilizar los activos fijos y todos sus movimientos que se reflejen en el balance general y en el estado de resultados es parte esencial de la información contable de la entidad, es así que esto implica que han sido adquiridos o comprados utilizando algun tipo de financiamiento o una mezcla 
de deuda y capital propios de los inversionistas; los activos fijos son el principal componente de los activos globales (Arroyo, 2014).

La propiedad planta y equipo es uno de los rubros de mayor importancia dentro de los activos que son controlados por la empresa y de los cuales se espera obtener beneficios futuros recordando la definición bajo las NIIF, debido a que permiten que la organización desarrolle sus actividades de manera óptima alcanzando los niveles de productividad y rentabilidad esperados. Para el sector privado se encuentra la Norma Internacional de Contabilidad NIC 16 y sus respectivos lineamientos que direccionan para el correcto manejo de los recursos que contribuyen al logro de los objetivos empresariales (Hansen, 2011).

Las NIIF permiten conocer las directrices en el tratamiento de la contabilización de los bienes tangibles desde su adquisición, vida útil y desgaste por su uso en las actividades operativas que genere beneficio económico, con la finalidad que los usuarios externos (organismos de control, fuentes de financiamiento, inversionista y socios y accionistas) adquieran información reflejada en los estados financieros por la inversión realizada en bienes tangibles así como los cambios que se ocasionan en este proceso de inversión. El principal inconveniente que se presenta en la adquisición de propiedad, planta y equipo es al momento de determinar su contabilización según las políticas contables establecidas por la entidad, así como su depreciación, revalorización, pérdida por deterioro u obsolescencia. La propiedad planta y equipo deberá ser tratada con estas bases para su comparabilidad y efectividad (IASB, 2014).

\section{Reconocimiento, medición y valoración de las propiedades, planta y equipo}

$\mathrm{Al}$ adquirir los bienes, se establece una política contable que determine el método de coste de los bienes, fijando así; el modelo de coste en el que dice que con posterioridad al reconocer como un bien tangible se procederá a contabilizar por su coste de compra menos la depreciación o amortización y el importe acumulado de las pérdidas por deterioro del valor; mientras que el método de revalorización realizado por profesionales o peritos en este campo manifiesta que el revalúo se harán con suficiente supervisión y control en el reconocimiento en libros, sin que difiera por sus convergencias al utilizar el valor razonable y cause confusiones en la administración (Junta de Normas Internacionales de Contabilidad (IASB), 2014).

\section{Sección 20 Arrendamientos y NIC 17}

Según la sección 20 de las NIIF para Pymes señala que al momento de contabilizar los arrendamientos se debe delimitar en dos grupos: el arrendamiento financiero y arrendamiento operativo, considerando que el arrendamiento financiero transfiere trascendentalmente las 
convicciones recurrentes en los riesgos y las ventajas que podrían ocasionarse en la propiedad de un activo, a diferencia de un arrendamiento operativo que no sucede el mismo acontecimiento, sino debe regirse a los derechos y obligaciones en donde el arrendador y el arrendatario se hacen acreedores en el momento que suscriben un contrato y se reconocen los pagos por la actividad que resulta en el transcurso del plazo establecido por arrendamiento, salvo excepciones específicas (IFRS,2009).

Cuando se clasifican los arrendamientos de terrenos o edificios, una entidad por lo general considera el terreno y la edificación como elementos separados. Los beneficios económicos o flujos de efectivo que genera por el arrendamiento se deben asignar por separado tanto para el terreno como para las edificaciones en proporción al valor razonable de los intereses del tenedor del arrendamiento del terreno y edificaciones. El elemento terreno por lo general se clasifica como un arrendamiento operativo a menos que se realice la transferencia de dominio al arrendatario al cumplir con el plazo de arrendamiento. Las edificaciones se clasifican como arrendamientos operativos o financieros aplicando el criterio de clasificación de esta norma (IASB, 2005).

En cuanto a la NIC 17, se define Arrendamiento (o alquiler) al acuerdo que se suscribe por medio de un contrato entre las partes que intervienen como: arrendador y arrendatario con el objetivo de percibir un beneficio económico por una serie de pagos o cuotas en plazos establecidos, considerando que se otorga el derecho de uso de la propiedad durante un período de tiempo determinado. Arrendamiento financiero es un convenio en el que se otorga la transferencia existencial de los riegos y ventajas al adquirir el uso del. Arrendamiento operativo es cualquier acuerdo de alquiler distinto al arrendamiento financiero (IASB, 2005).

\section{Sección 16 Propiedades de inversión - NIC 40}

Sólo las propiedades de inversión se pueden medir con fiabilidad sin costo o esfuerzo desproporcionado, se contabilizarán de acuerdo con esta sección por su valor razonable ocasionando que se reflejen en el balance de resultados al momento de presentar su información. De ahí que hay una gran diferencia entre la propiedad planta y equipo y las propiedades de inversión que tienen las empresas y la importancia de su correcta clasificación (IFRS, 2009).

En cuanto a la NIC 40, se reconoce a los flujos de efectivo, medios líquidos equivalentes entregados por el valor razonable al momento que se genera la contraprestación al adquirir o construir un bien inmueble (Torres, 2010); Importe en libros, se produce al momento de realizar el reconocimiento por medio del proceso de contabilización del valor por el cual se compró un activo en el estado de situación financiera; Inversiones inmobiliarias, son las operaciones que se obtiene de un bien inmuebles por medio de rentas, plusvalías o ambas; 
Valor razonable, es el importe en el cual se realiza la transferencia entre las partes interesadas adquiriendo obligaciones y derechos en una transacción en condiciones de independencia mutua; en la contabilidad tradicional es conocido como el valor en libros.

\section{NIC 36 deterioro del valor de los activos}

Se contabilizará un activo por encima de su importe recuperable cuando su importe en libros exceda del importe que se pueda recuperar del mismo a través de su utilización o de su venta. La entidad deberá reconocer como pérdida por deterioro de un bien inmueble siempre y cuando la empresa presente información relevante y confiable que sustente el cálculo determinado por deterioro del bien. Se podrá revertir la pérdida por deterioro de un activo siempre y cuando en el período anterior haya sido considerado como un impuesto diferido (IASCF, 2009).

\section{Metodologia}

El diseño de investigación fue mixto, ya que se recolectaron datos cualitativos en la fase inicial de investigación y datos cuantitativos en el diagnóstico, para lo cual se hizo un uso simultáneo de los métodos inductivo y deductivo, análitico - sintético e histórico - lógico.

El alcance de la investigación fue descriptivo-explicativo (DEXPLIS), en una primera etapa se levantó información cualitativa relacionada con el tratamiento de propiedad, planta y equipo en la unidad de análisis, y en la segunda fase se recogieron y evaluaron datos cuantitativos en un solo momento del tiempo, los mismos que se integraron y dieron paso a la interpretación y presentación de resultados.

Se determinó como unidad de análisis la Cía. Ltda. Previsión Exequial La Esperanza, de la ciudad de Loja., el universo de estudio estuvo conformado por 16 empleados, entre ellos trabajadores que laboran en el departamento financiero, departamento contable, administrativo, el jefe de operaciones y socios de la compañía que tienen relación directa con el manejo de la información contable - financiera.

\section{Resultados}

Entre los principales resultados que se obtuvieron en la investigación, resaltan los siguientes:

- La empresa determina la vida útil de los bienes respaldándose en la normativa vigente que establece la Ley Orgánica de Régimen Tributario Interno.

- Durante los últimos años no se ha contabilizado adecuadamente la revalorización de activos obtenida por profesionales especializados en este campo.

- Erróneamente se ha realizado la depreciación de bienes, antes de que éstos sean recibidos por la empresa o instalados para su uso. 
- No se evidencia el uso de cuentas transitorias para identificar los rubros de materiales, mano de obra y otros costos en la construcción de parcelas, bóvedas y nicho cinerarios y osarios en pared, tal como lo establecen las NIIF para la construcción en curso, lo que dificulta posteriormente su reclasificación como una cuenta de activo listo para operar y producir beneficios económicos.

- No se considera un costo por desmantelamiento o rehabilitación al momento de realizar el reconocimiento inicial o desalojo del elemento de la propiedad, planta y equipo en el lugar en que se instalarán las bóvedas y nicho cinerarios.

- Los activos no se encuentran identificados, codificados ni seriados, lo cual dificulta identificar con claridad y de una forma ágil la ubicación, características y estado de los mismos.

- No se encuentran establecidos procedimientos de control de los bienes por lo que, no se han establecido responsabilidades para su uso, manejo y principalmente para su registro contable.

Los resultados obtenidos tienen un efecto significativo en la estructura de la información contable y en el desempeño de la empresa, en este sentido, se refuerza la teoría de la adopción de las NIIF, como herramienta fundamental para disponer de información integra, fiable y comprensible.

A continuación, se presentan los procedimientos de gestión contable, para el tratamiento de propiedad, planta y equipo bajo las NIFF para la empresa Previsión Exequial La Esperanza, Cía. Ltda.

Figura 1. Procedimientos de gestión contable de propiedad, planta y equipo bajo NIIF

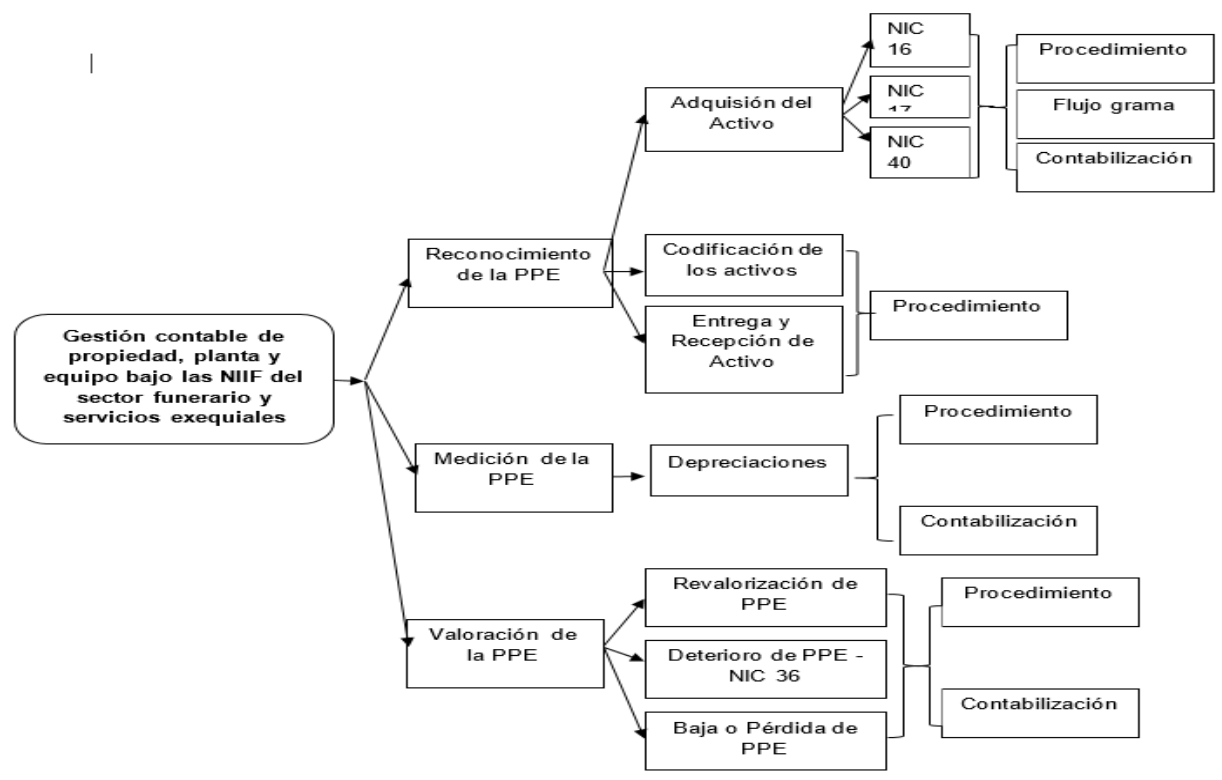

Fuente: Elaboración propia 
Tabla 2. Norma Internacional de Contabilidad 16.

Gestión contable de propiedad, planta y equipo bajo las NIIF en el sector funerario y servicios exequiales

\section{Código: $\quad$ GCC001}

Versión: 001

Operativo

Contable

$\mathbf{X}$

Objetivo del procedimiento. - Señalar las pautas para la adquisición de un nuevo activo fijo bajo NIC 16.

\section{Descripción del procedimiento} operativo o producción.
Documentos o actividad

- Reunión de socios o departamentales (determinar la responsabilidad de la adquisición) - Acta de aprobación de adquisición.

2. La Persona encargada de la adquisición solicitará las

Proforma o cotización proformas o cotización a los proveedores verificando precio y características.

3. Autorizar la proforma o cotización por la persona solicitante y jefe inmediato entregar a tesorería.

Correo de autorización o proforma sumillada.

4. Tesorería recibirá la proforma o cotización aprobada y - Proforma o cotización y factura autorizada para solicitar factura y entregar a contabilidad.

5. Contabilidad receptará de tesorería proforma y factura

- Proforma o cotización y factura

6. El departamento contable revisará, analizará y - Registros contables determinará de acuerdo a las políticas y normas si cumple con los principios para ser contabilizado como propiedad, planta y equipo bajo NIIF.

\section{Fuente: Elaboración Propia.}

Tabla 3. Contabilización NIC 16

\begin{tabular}{llcc}
\hline Fecha & \multicolumn{1}{c}{ Detalle } & Debe & Haber \\
\hline & $\begin{array}{l}\text { Propiedad, planta y equipo } \\
\text { IVA }\end{array}$ & xxx \\
Pancos adquisición de activos & & \\
& $\begin{array}{l}\text { Pdministrativos, operativos } \\
\text { producción }\end{array}$
\end{tabular}


Figura 2. Adquisición de propiedad, planta y equipo NIC 16.

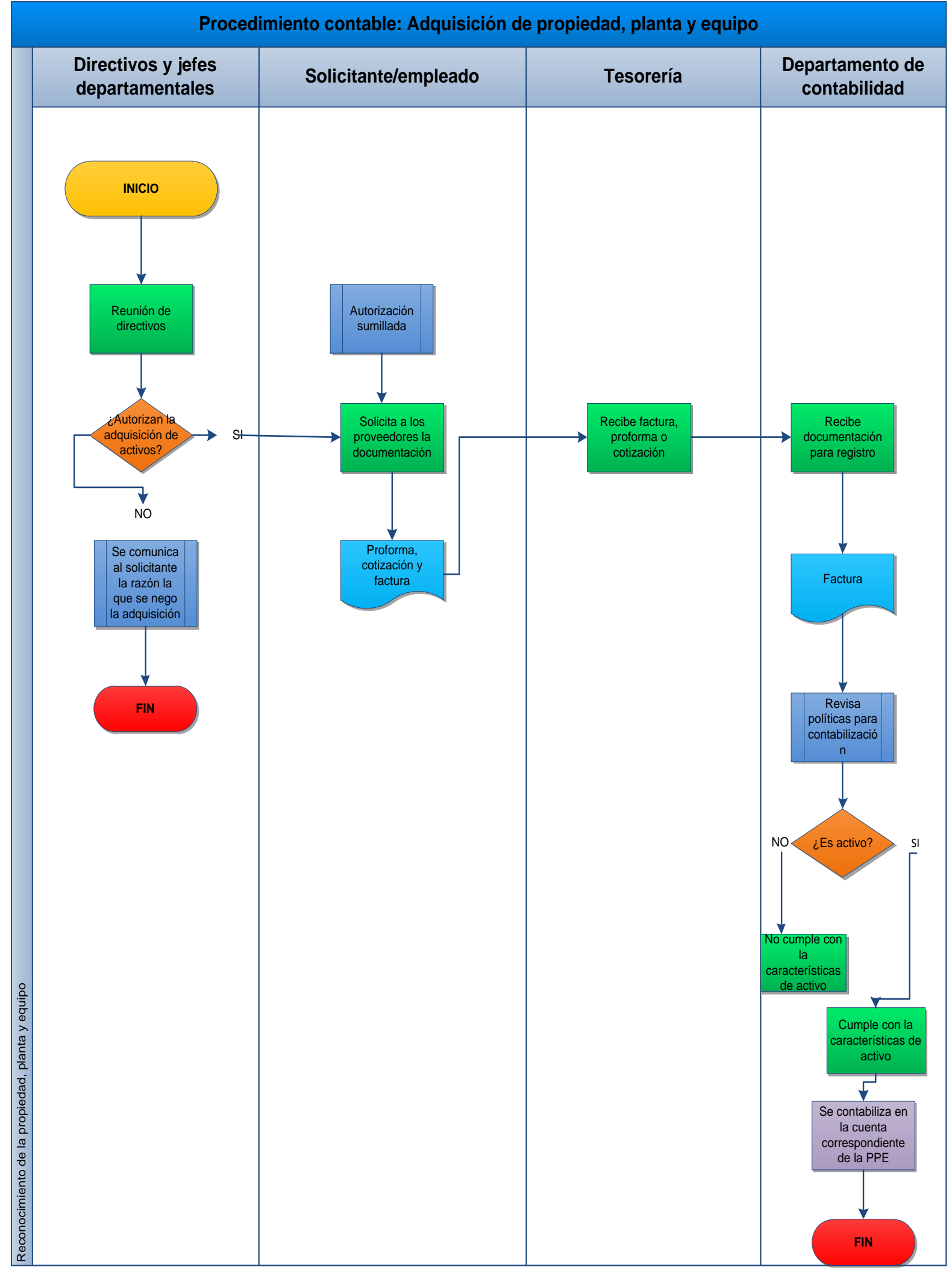


Tabla 4. Norma Internacional de Contabilidad 17.

Gestión contable de propiedad, planta y equipo bajo las NIIF en el sector funerario y servicios exequiales

\section{Código: GC001}

Versión: 001

Tipo de proceso:

Operativo

Contable

Objetivo del procedimiento. - Señalar las pautas para la contabilización de propiedades por arrendamiento operativo NIC 17.

Descripción del procedimiento

1. El administrador del camposanto deberá segregar o diferencias un sector de las propiedades construidas como bóvedas que sean destinadas solo para arrendamiento operativo.

2. La jefa financiera solicitará la información sobre las propiedades para arrendamiento operativo e informará al departamento contable.

3. El departamento contable analizará las políticas cuando se deba contabilizar propiedades por arrendamiento operativo.

\section{Documentos o actividad}

- Croquis de propiedades de arrendamiento operativo.

4. El departamento contable deberá reconocer y registrar los rubros por arrendamiento - Registros contables. operativo que se reflejen en los estados

- Informe de características y reconocimiento de las propiedades por arrendamiento.

financieros.

Tabla 5. Contabilización NIC 17.

Fecha Detalle Debe Haber

-------X------

Bancos

Propiedades por arrendamiento operativo

XXX

(Servicios exequiales arrendamiento bóveda)

$\mathbf{P} / \mathbf{r}$. Propiedades de arrendamiento operativo. 
Figura 3. Propiedades de arrendamiento operativo NIC 17.

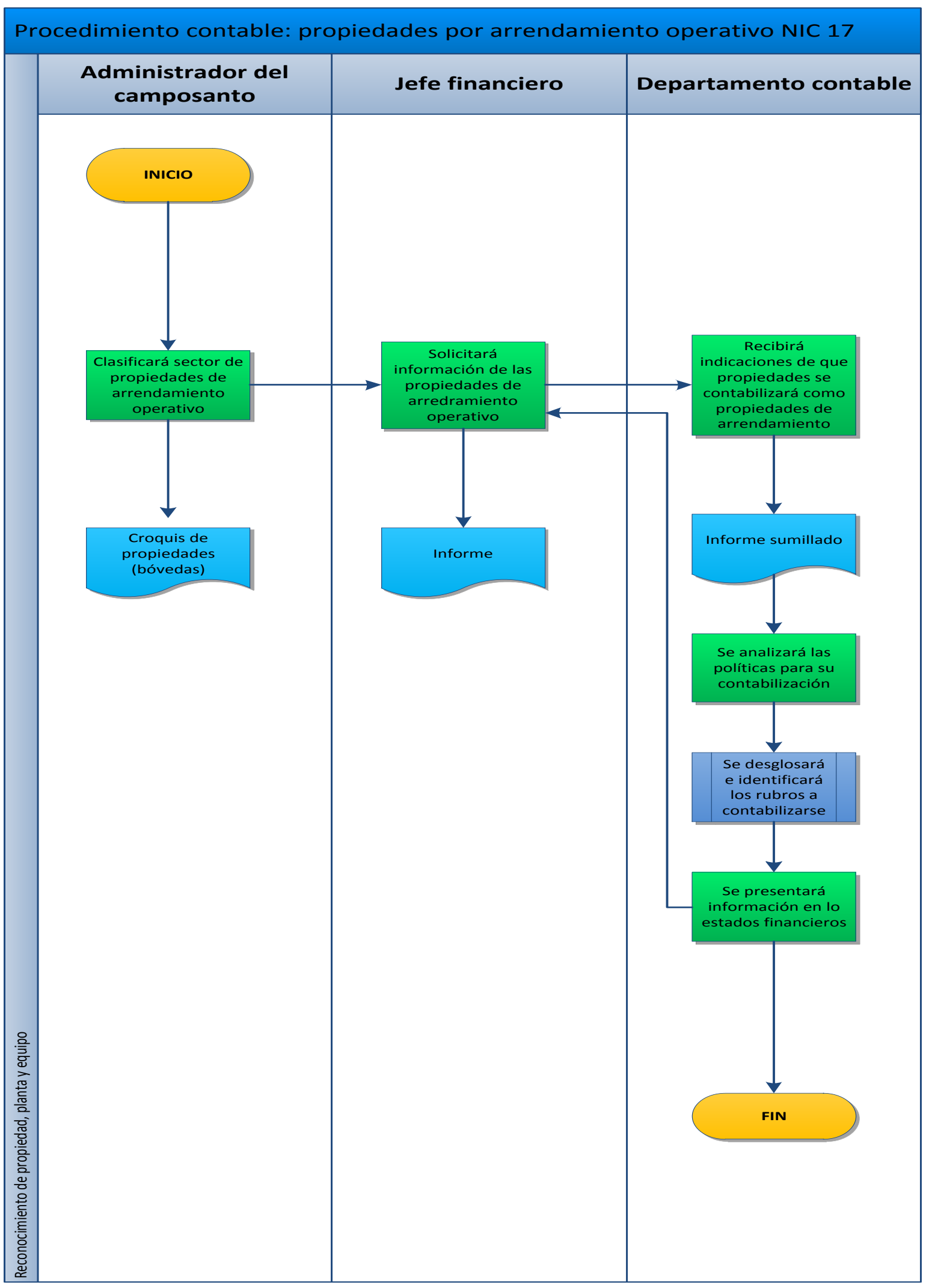


Tabla 6. Norma Internacional de Contabilidad 40.

Gestión contable de propiedad, planta y equipo bajo las NIIF en el sector funerario y servicios exequiales

\section{Código: $\quad$ GC001}

Versión: 001

$\begin{array}{llll}\text { Tipo de proceso: } & \text { Operativo } & \text { Contable } & \text { X }\end{array}$

Objetivo del procedimiento. - Indicar como se debe contabilizar un activo fijo por inversión (parcelas familiares, nichos cinerarios, osarios o bóvedas) NIC 40.

\section{Descripción del procedimiento}

\section{Documentos o actividad}

1. El administrador del camposanto presentará la planificación para la construcción de propiedades de - Autorización por la junta directiva. inversión según la NIC 40 a los directivos.

2. El administrador presentará el presupuesto a ser - Presupuesto aprobado autorizado por jefe financiero.

3. El jefe financiero informará a los socios, tesorera y departamento contable el presupuesto autorizado para

- Reunión departamental la construcción de propiedades de inversión.

4. La tesorera recibirá la documentación soporte en el proceso de construcción informando a contabilidad las especificaciones.

5. El departamento contable recibirá la documentación soporte y revisará las políticas y normativa para la construcción de propiedades de inversión.

Facturas por materiales, mano de obra o costos indirectos.

Añadirá una cuenta específica para construcción en curso para las propiedades de inversión.

6. El departamento fiscalizará el cumplimiento del presupuesto, para una vez cumplido con las etapas de construcción de reclasificará la cuenta de construcción

- Reclasificación de cuenta. en curso a un activo fijo terminado.

Tabla 7. Contabilización NIC 40.

\begin{tabular}{|c|c|c|c|}
\hline Fecha & Detalle & Debe & Haber \\
\hline & Construcción en curso de nichos & $\mathrm{xxx}$ & \\
\hline & Bancos & & $\mathrm{xxx}$ \\
\hline & $\begin{array}{l}\mathbf{P} / \mathbf{r} \text {. Construcción en curso de } \\
\text { propiedades de inversión. }\end{array}$ & $\mathrm{xxx}$ & \\
\hline & --------X------ & & $\mathrm{xxx}$ \\
\hline & Nichos cinerarios & & \\
\hline & Construcción en curso de nichos & & \\
\hline & $\mathbf{P} / \mathbf{r}$. las propiedades de inversión. & & \\
\hline
\end{tabular}


Figura 4. Propiedades de inversión NIC 40.

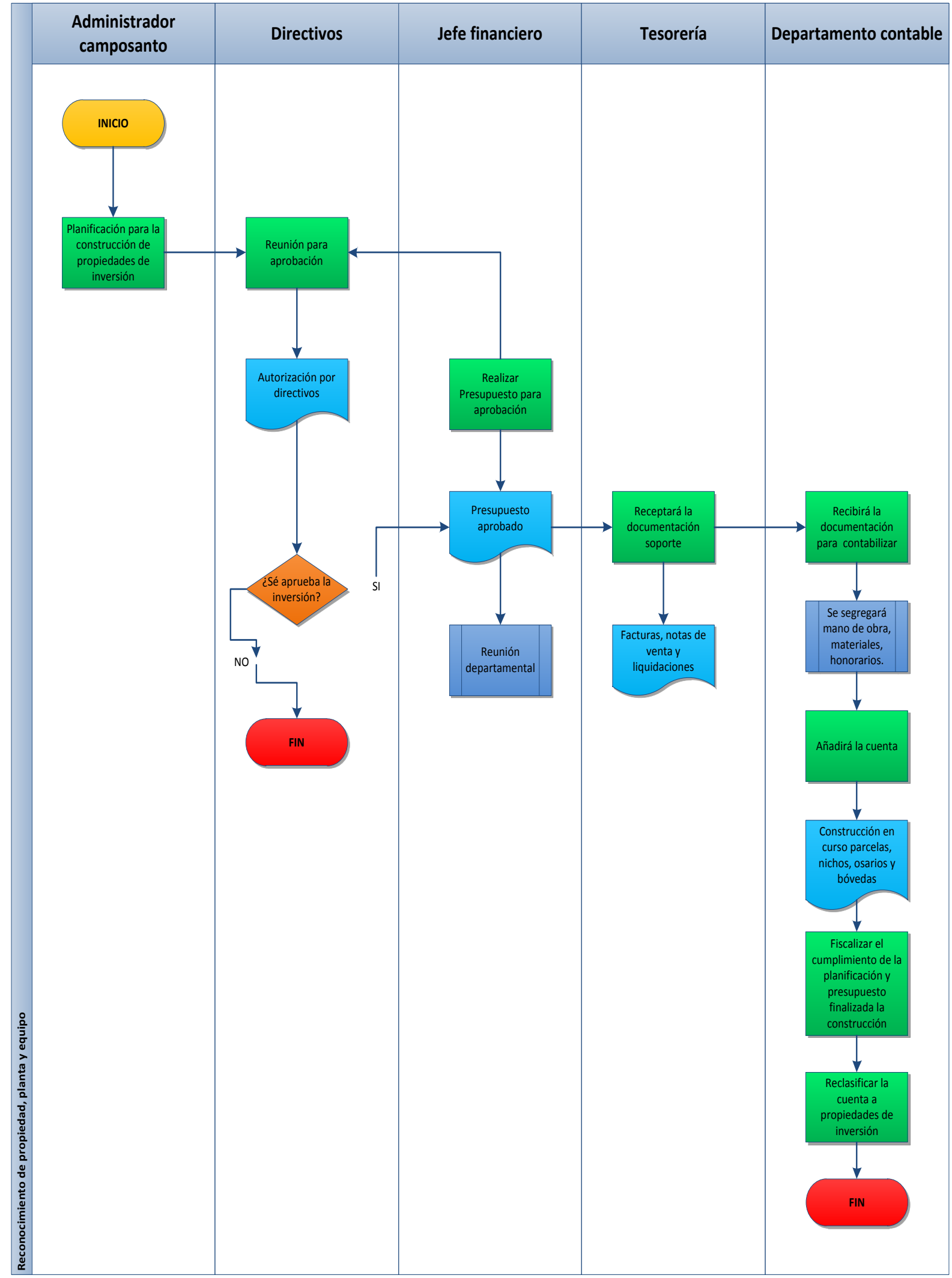


Tabla 8. Codificación de propiedad, planta y equipo.

\begin{tabular}{|c|c|c|}
\hline & Código: & GC001 \\
\hline $\begin{array}{c}\text { Gestión contable de propiedad, planta y equipo bajo las NIIF en el } \\
\text { sector funerario y servicios exequiales }\end{array}$ & Versión: & 001 \\
\hline
\end{tabular}

$\begin{array}{llll}\text { Tipo de proceso: } & \text { Operativo } & \text { Contable }\end{array}$

Objetivo del procedimiento. - Señalar los pasos a seguir para codificar los activos en el momento de su adquisición.

\section{Descripción del procedimiento}

1. Se hará llegar la documentación por adquisición de activos fijos a tesorería.

2. La tesorera verificará que la factura contenga las especificaciones claras del activo como: color, material, dimensiones, marca, serial en el caso de equipo de cómputo, de oficina o maquinaria.

3. Sino tiene ese tipo de información se verificará físicamente y se obtendrá las particularidades para - Verificación física informar a contabilidad.

4. Una vez verificada la información se entregará al departamento contable para su contabilización y - Entrega de factura codificación.

5. El departamento contable contabilizará el activo fijo, designará un código y se entregará al bodeguero o persona responsable del activo para que lo ubique en el mismo.

6. El bodeguero o persona responsable del activo deberá ubicar el código en un lugar que no pueda ser manipulado y pueda conservarse para identificarse con facilidad.

- Factura

- Revisión documental

\section{Documentos o actividad}

- Supervisión, contabilización y codificación.

Tabla 9. Ubicación del código en activos fijo.

Tipo de activo

Ubicación de etiquetado

Muebles de oficina, equipo de oficina $y$ equipo de cómputo.

En la parte superior derecha

Sillas

Debajo del asiento

Maquinaria y equipos

Junto con la marca o número de serie

Vehículo

Parte superior del vidrio delantero

Varios

Cuando el bien mueble este integrado por varias partes que puedan separarse se deberá codificar cada parte. 
Figura 5. Serie y código de Activos fijos.
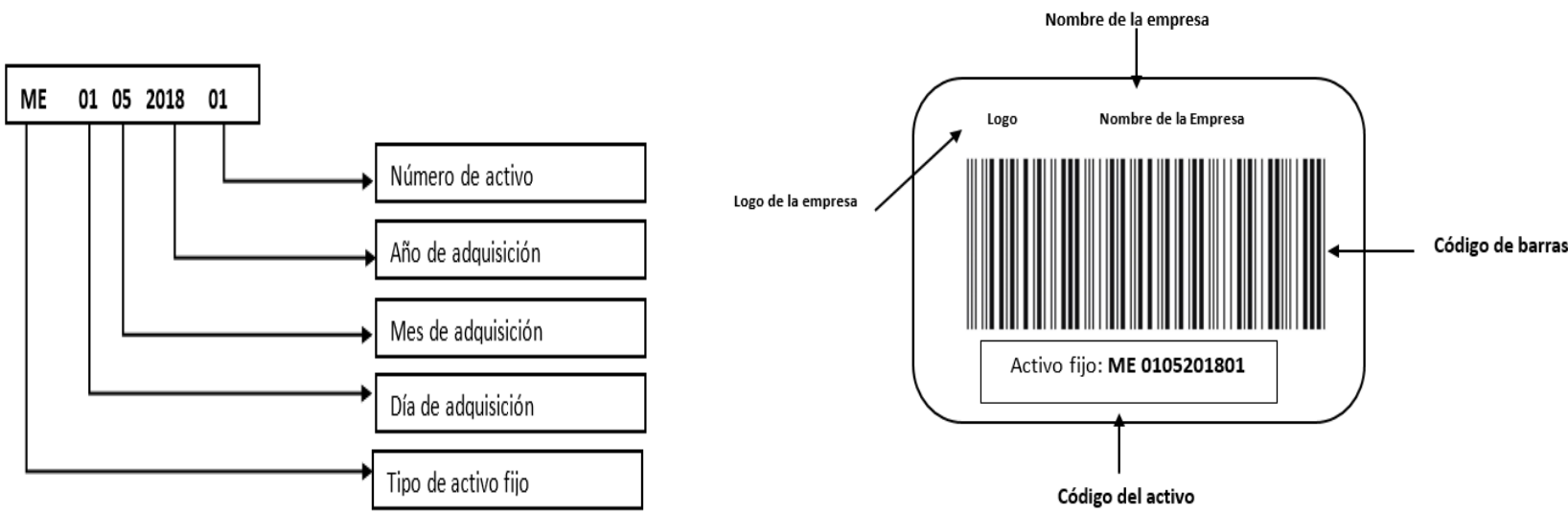

Tabla 10. Entrega y Recepción de activos fijos.

\begin{tabular}{ccccc}
$\begin{array}{c}\text { Gestión contable de propiedad, planta y equipo bajo las NIIF en el } \\
\text { sector funerario y servicios exequiales }\end{array}$ & \multicolumn{2}{c}{\begin{tabular}{c} 
Código: \\
\cline { 2 - 4 } Tipo de proceso:
\end{tabular}} & Gersión: & GC001 \\
\hline Operativo & $\mathrm{X}$ & & Contable
\end{tabular}

Objetivo del procedimiento. - Indicar los lineamientos para la entrega y recepción de la propiedad, planta y equipo mediante acta.

\section{Descripción del procedimiento}

\section{Documentos o actividad}

1. Se comunicará por parte del departamento de Talento Humano al encargado de los activos fijos el ingreso o salida de personal, así como el cambio de puestos de - $\quad$ Comunicación al bodeguero. trabajo.

2. El bodeguero suministrará el equipo de trabajo de acuerdo a la actividad que va a realizar el personal bajo las condiciones necesarias para operar.

3. El bodeguero revisará los activos fijos que se encuentren en buen estado y codificados en la entrega o recepción.

4. Se entregará un acta de constatación de los bienes - Acta de entrega y recepción de los activos entregados o recibidos sumillado por ambas partes. fijos

5. Se llevará un control mediante un registro de los bienes del estado en que se encuentra y en donde se encuentran - Registro de bienes muebles. ubicados.

6. EL bodeguero informará al departamento de contabilidad cualquier tipo de novedad en caso de que existiera bienes en mal estado, pérdidas o robos para - Informe a contabilidad proceder a dar la correspondiente baja del mismo. 
Tabla 11. Depreciación de propiedad, planta y equipo.

Gestión contable de propiedad, planta y equipo bajo las NIIF en el sector funerario y servicios exequiales

\begin{tabular}{ll} 
Código: & GC001 \\
\hline Versión: & 001
\end{tabular}

Tipo de proceso:

Operativo

contable

$\mathbf{X}$

Objetivo del procedimiento.- Señalar las pautas para realizar las depreciaciones de propiedad, planta y equipo.

\section{Descripción del procedimiento}

\section{Documentos o actividad}

1. Tesorería recibirá la factura autorizada por la parte - Factura de compra solicitante de la compra del bien muebles o por la construcción en proceso del activo fijo.

2. Contabilidad recibirá factura y documento de respaldo - Registro de la compra de bienes muebles e para registro contable. inmuebles.

3. Si es bien mueble se solicitará información si está instalado para su operación.

4. Si ya está instalado para comenzar a operar o a ser - Depreciación de los activos. utilizado se procederá a depreciar de acuerdo a los porcentajes correspondiente bajo la normativa y políticas.

5. Si se trata de un bien inmueble en proceso de - Reclasificación de cuenta construcción en construcción como lo es bóvedas, nichos, osarios o curso. parcelas familiares se comenzará a depreciar cuando haya concluido su construcción y se haya reclasificado la cuenta de construcción en curso.

6. Se realizará los cálculos y registro contable de las - Archivo de historial de activos con sus depreciaciones diferenciando por tipo de activo. respectivas depreciaciones.

Tabla 12. Contabilización de depreciación de propiedad, planta y equipo.

\begin{tabular}{|c|c|c|c|}
\hline Fecha & Detalle & Debe & Haber \\
\hline \multicolumn{4}{|c|}{-------X------ } \\
\hline & Gasto depreciación activos fijos & $\mathrm{xxx}$ & \\
\hline & Depreciación Acum. Activos fijos & & $\mathrm{xxx}$ \\
\hline & $\begin{array}{l}\text { P/r. Depreciación de propiedad, planta y } \\
\text { equipo. }\end{array}$ & & \\
\hline
\end{tabular}


Tabla 13. Revalorización de propiedad, planta y equipo.

\begin{tabular}{cccc}
\hline Gestión contable de propiedad, planta y equipo bajo las NIIF en el & \multicolumn{1}{l}{ Código: } & \multicolumn{1}{l}{ GC001 } \\
\cline { 2 - 3 } sector funerario y servicios exequiales & Versión: & 001 & \\
\hline Tipo de proceso: & Operativo & Contable & X \\
\hline
\end{tabular}

Objetivo del procedimiento. - Indicar las pautas para la revalorización de la propiedad, planta y equipo.

\section{Descripción del procedimiento}

1. Departamento financiero solicita al departamento contable se contrate una empresa autorizada por la Superintendencia de compañías con personal idóneo para el proceso de revalorización de Bienes muebles e inmuebles de la empresa.

2. El departamento de contabilidad con el resultado obtenido por el personal especializado de realizar la revalorización de activos fijos procederá a contabilizar.

3. Se determinará el valor comercial de los cada uno de - Asiento por revalorización los activos.

4. Se analizará si excede el costo ajustado en libros se - Asiento de provisión contabilizará el superávit por revalorización de la propiedad, planta y equipo

5. Si se establece que es inferior a la valorización - Asiento de reversa registrada sin afectar al costo ajustado se reversará

6. Este proceso de revalorización se lo realizará cada tres años.

Tabla 14. Contabilización por revalorización

Fecha Detalle

Debe

Haber

--------X------

Propiedad, planta y equipo

Superávit (ORI)

$\operatorname{XXX}$

P/r. Revalorización de activos.

Superávit

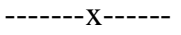

Propiedad, planta y equipo

$\mathrm{XXX}$

P/r. Reversa por revalorización de activos.

\section{Documentos o actividad} revalorización de activos.
- Informe de revalorización de activos fijos. 
Tabla 15. Norma Internacional de Contabilidad 36.

\section{Gestión contable de propiedad, planta y equipo bajo las NIIF en el Código: $\quad$ GC001 sector funerario y servicios exequiales

Versión: 001

Tipo de proceso:

Operativo

Contable

$\mathbf{X}$

Objetivo del procedimiento.- Lineamientos en el deterioro de la propiedad, planta y equipo NIC 36

\section{Descripción del procedimiento}

1. El departamento contable poseerá un registro de los bienes muebles e inmuebles de la entidad.

\section{Documentos o actividad}

- $\quad$ Registro de bienes muebles e inmuebles.

2. Este registro de activos fijos deberá estar clasificado por los bienes de uso para las actividades administrativas u operativas y por los bienes que prestan los servicios exequiales como parcelas - Clasificación de bienes por actividades. familiares, nichos de pared, nichos bajo capillas, bóvedas y osarios.

3. Los bienes utilizados para prestar servicios exequiales deberán ser contabilizados por un importe que no sea superior al importe recuperable

4. El activo estará contabilizado por encima de su importe recuperable cuando su importe en libros exceda del importe en el proceso de su utilización se considerará como deteriorado

5. El importe en libros se reducirá y se contabilizar pérdida por deterioro del valor.

6. Se contabilizará por deterioro que constituye un gasto contra deterioro acumulado.

7. La pérdida por deterioro se reconocerá en los resultados del ejercicio. Si la pérdida por deterioro se realiza a un activo revalorizado este afectará en la disminución por revalorización de acuerdo a la NIC 16.

Tabla 16. Contabilización NIC 36

\begin{tabular}{|c|c|c|c|}
\hline Fecha & Detalle & Debe & Haber \\
\hline \multicolumn{4}{|c|}{-------X------ } \\
\hline & Gasto por deterioro & $\mathrm{xxx}$ & \\
\hline & Deterioro acumulado de PPE & & $\mathrm{xxx}$ \\
\hline & $\begin{array}{l}\text { P/r. Deterioro de la propiedad, planta y } \\
\text { equipo }\end{array}$ & & \\
\hline
\end{tabular}


Tabla 17. Baja de la propiedad, planta y equipo.

\begin{tabular}{cccc} 
Gestión contable de propiedad, planta y equipo bajo las NIIF en el & \multicolumn{2}{c}{ Código: } & \multicolumn{2}{c}{ GC001 } \\
\cline { 2 - 4 } sector funerario y servicios exequiales & Versión: & 001 \\
\hline Tipo de proceso: & Operativo & Contable & X
\end{tabular}

Objetivo del procedimiento. - Directrices para la baja de la propiedad, planta y equipo por pérdida, deterioro, desuso, finalización de vida útil o venta.

Descripción del procedimiento

Documentos o actividad

1. El encargado o custodio de los activos fijos deberá reportar al departamento contable cuando los activos - Informe del estado del activo fijo. fijos hayan sufrido deterioro, pérdida o robo.

2. El departamento contable fiscalizará mediante la verificación física de los activos reportados por el - Fiscalización o auditoría de los bienes. custodio.

3. Solicitará autorización al departamento financiero para la baja del activo.

- $\quad$ Autorización para la baja de los bienes.

4. Teniendo la autorización correspondiente determinará mediante declaración juramentada y notariada de la persona involucrada (custodio y contador) que el activo - Declaración juramentada. fue robado o pérdida para dar de baja en los libros contables.

5. Teniendo la declaración notariada se contabilizará la baja del activo.

Contabilización por el motivo de la baja.

6. Siendo por venta de determinará la utilidad o pérdida obtenida por el activo.

Cálculos para determinar utilidad o pérdida.

Tabla 18. Contabilización de la baja de propiedad, planta y equipo.

\begin{tabular}{|c|c|c|c|}
\hline Fecha & Detalle & Debe & Haber \\
\hline \multicolumn{4}{|c|}{-------X------ } \\
\hline & Bancos & \multirow{6}{*}{$\mathrm{xxx}$} & \multirow{6}{*}{$\mathrm{xxx}$} \\
\hline & Depreciación Acumulada de la PPE & & \\
\hline & Propiedad, planta y equipo & & \\
\hline & Utilidad por venta de PPE & & \\
\hline & Depreciación recuperada & & \\
\hline & P/r. Utilidad venta de activos fijos. & & \\
\hline & -------X------ & \multirow[t]{2}{*}{$\mathrm{xxx}$} & \\
\hline & Pérdida por PPE & & \\
\hline & Depreciación de la PPE & \multirow[t]{3}{*}{$\mathrm{xxx}$} & XXX \\
\hline & Propiedad, planta y equipo & & \\
\hline & Depreciación por pérdida & & $\mathrm{xxx}$ \\
\hline
\end{tabular}

$\mathbf{P} / \mathbf{r}$. Pérdida por venta de activos fijos. 


\section{Conclusiones.}

- Las normas internacionales NIC y NIIF contribuyen a que la información generada en las entidades del sector funerario y servicios exequiales, sea comparable, comprensible, relevante y confiable reflejada en los estados financieros que sirven como sustento, para el cumplimiento de acuerdo a lo exigido y establecido por los organismos de control en Ecuador.

- La propiedad planta y equipo constituye uno de los rubros de mayor inversión que requieren en todo tipo de organización para su operatividad, con o sin fines de lucro, y que contribuyen al logro de metas establecidas, con la finalidad de ser recuperables en un futuro cercano.

- La entidad objeto de estudio procedió con la adopción por primera vez de las NIIF, sin embargo, no se ha analizado e implementado de una forma adecuada las NIIF Y NIC para el tratamiento de la propiedad, planta y equipo para el sector funerario y servicios exequiales, lo que afecta a la integridad de la información que revela en sus estados financieros.

- Las empresas del sector funerario y servicios exequiales deben tener un amplio conocimiento en la aplicación principalmente de las NIC 16, NIC 17, NIC 36 Y NIC 40 para la presentación de información contable, ya que así se garantiza una efectiva gestión contable y tributaria de propiedad, planta y equipo y observar si está produciendo beneficios económicos.

\section{Referencias bibliográficas.}

Arroyo, R. (2014). Valoración de los activos fijos de la empresa electrica regional del norte EMELNORTE, en la agencia PIMAMPIRO. Universidad tecnica del norte, 8. Obtenido de

http://repositorio.utn.edu.ec/bitstream/123456789/4090/2/03\%20AGN\%20007\%20AR T\%C3\%8DCULO\%20CIENT\%C3\%8DFICO.pdf.

Bohórquez, N. (2015). Implementación de norma internacional de inventarios en Colombia. INNOVAR. Revista de Ciencias Administrativas y Sociales, 79-80. Obtenido de http://www.redalyc.org/articulo.oa?id=81839197006

Bravo, M. (2011). Contabilidda General. Quito: Escobar.

Cano, A. (2013). Contabilidad gerencial y presupuestaria. Bogotá: Ediciones de la U.

Coral, L. y Gudiño, E. (2014). Contabilidad Universitaria (séptima ed.). Bogotá: McGrawHill. 
Díaz , O. y Duran, A. (2012). Estado actual de la aplicación de las NIIF en la preparación de estados financieros de las empresas peruanas. Contabilidad y Negocios, 8. Obtenido de http://www.redalyc.org/articulo.oa?id=281621783002

Fundación IFRS. (2009). Material de infromación sobre la NIFF para las PYMES.

Gómez, M. (2003). Algunos comentarios sobre la potencialidad de la investigación en contabilidad. NNOVAR. Revista de Ciencias Administrativas y Sociales,, 139. Obtenido de http://www.redalyc.org/articulo.oa?id=81802110

Hansen, H. (2011). NIIF Teoría y Práctica. Guayaquil: Edificio Coloncorp.

Hansen, H. (2012). NIIF para pymes. Guayaquil: Parque Empresarial Colón.

IASB. (2005). Norma Internacional de Contabilidad 17.

IASB. (2014). Norma Internacional de Contabilidad NIC 16.

IFRS. (2009). Obtenido de http://crconsultorescolombia.com/wpcontent/uploads/2014/10/16_Propiedades-de-Inversion_2013.pdf

Monge, P. (2005). Las Normas Internacionales de Contabilidad. Actualidad Contable Faces, 36. Obtenido de http://www.redalyc.org/articulo.oa?id=25701005

Peña, C.(2013). Análisis de las diferencias entre las Normas Internacionales de Información Financiera (NIIF) y los Principios de Contabilidad (VEN-NIIF). Revista del Centro de Investigación, 148. Obtenido de http://www.redalyc.org/articulo.oa?id=34231070009

Peña, A. y Bastidas, M. (2007). La ética: fundamento en la adopción de las normas internacionales de contabilidad. Actualidad Contable Faces, 119. Obtenido de http://www.redalyc.org/articulo.oa?id=25701411

Ramirez, H. y Suárez, B. (2012). Guía NIIF para Pymes. (U. L. Colombia, Ed.) Centro de Investigaciones Facultad de Ciencias Económicas, Administrativas y Contables.

Rueda, G. (2012). Los aportes de la teoría de la acción comunicativa y sus conceptos a una contabilidad para el entendimiento y la integración de la sociedad. Universitas Humanística, 231. Obtenido de http://www.redalyc.org/articulo.oa?id=79125420010

Santos, C.(2016). La contabilidad creativa, el directorio y la ética organizacional. Revista de la dirección, 50. Obtenido de http://scieloprueba.sld.cu/pdf/rdir/v10n2/rdir04216.pdf

Santos, N. (2008). Decisión de Comprar o Alquilar Activos Fijos. Industrial Data, 9. Obtenido de http://www.redalyc.org/articulo.oa?id=81619829002

Torres, A. (2010). Contabilidad de Costos. Mexico: McGraw Hill. 


\section{PARA CITAR EL ARTÍCULO INDEXADO.}

Abad Retete, J., Narváez Zurita, C., \& Erazo Álvarez, J. (2019). Gestión contable de propiedad, planta y equipo bajo las Normas Internacionales de Información Financiera (NIIF) para el sector funerario y de servicios exequiales. Visionario Digital, 3(2.1.), 35-59. https://doi.org/10.33262/visionariodigital.v3i2.1.543

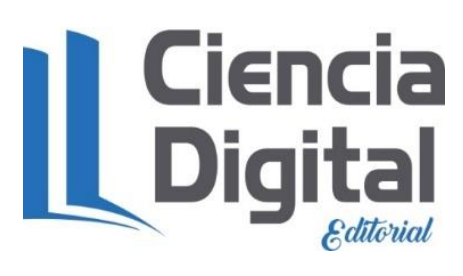

El artículo que se publica es de exclusiva responsabilidad de los autores y no necesariamente reflejan el pensamiento de la Revista Visionario Digital.

El artículo queda en propiedad de la revista y, por tanto, su publicación parcial y/o total en otro medio tiene que ser autorizado por el director de la Revista Visionario Digital.
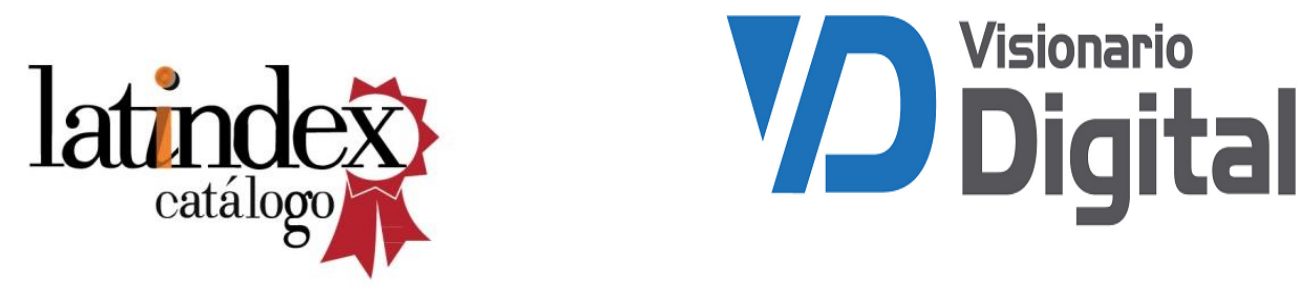